\title{
CORRECTION
}

\section{Correction to: Isokinetic and functional shoulder outcomes after arthroscopic capsulolabral stabilization}

Breborowicz Ewa ${ }^{1}$ [D $\cdot$ Lubiatowski Przemyslaw ${ }^{1,2} \cdot$ Jokiel Marta $^{1,3} \cdot$ Breborowicz Maciej $^{1} \cdot$ Stefaniak Jakub $^{1}$. Zygmunt Adam ${ }^{1} \cdot$ Wojtaszek Marcin ${ }^{1} \cdot$ Kaczmarek Piotr $^{2} \cdot$ Romanowski Leszek $^{1}$

Published online: 1 February 2022

(c) The Author(s) 2022

\section{Correction to: Archives of Orthopaedic and Trauma Surgery https://doi.org/10.1007/s00402-021-04290-4}

The original version of this article unfortunately contained a mistake. Two rows are missing in the Table 2 .
The corrected Table 2 is given in the next page. The original article has been corrected.

The original article can be found online at https://doi.org/10.1007/ s00402-021-04290-4.

Breborowicz Ewa

ewabreborowicz@gmail.com

1 Orthopaedics, Traumatology and Hand Surgery Department,

Poznan University of Medical Sciences,, 28 Czerwca 1956

no 135/147, 61-545 Poznań, Poland

2 Rehasport Clinic, Gorecka 30, 60-201 Poznań, Poland

3 Physiotherapy Department, Poznan University of Medical Sciences, 28 Czerwca 1956 no 135/147, 61-545 Poznań, Poland 


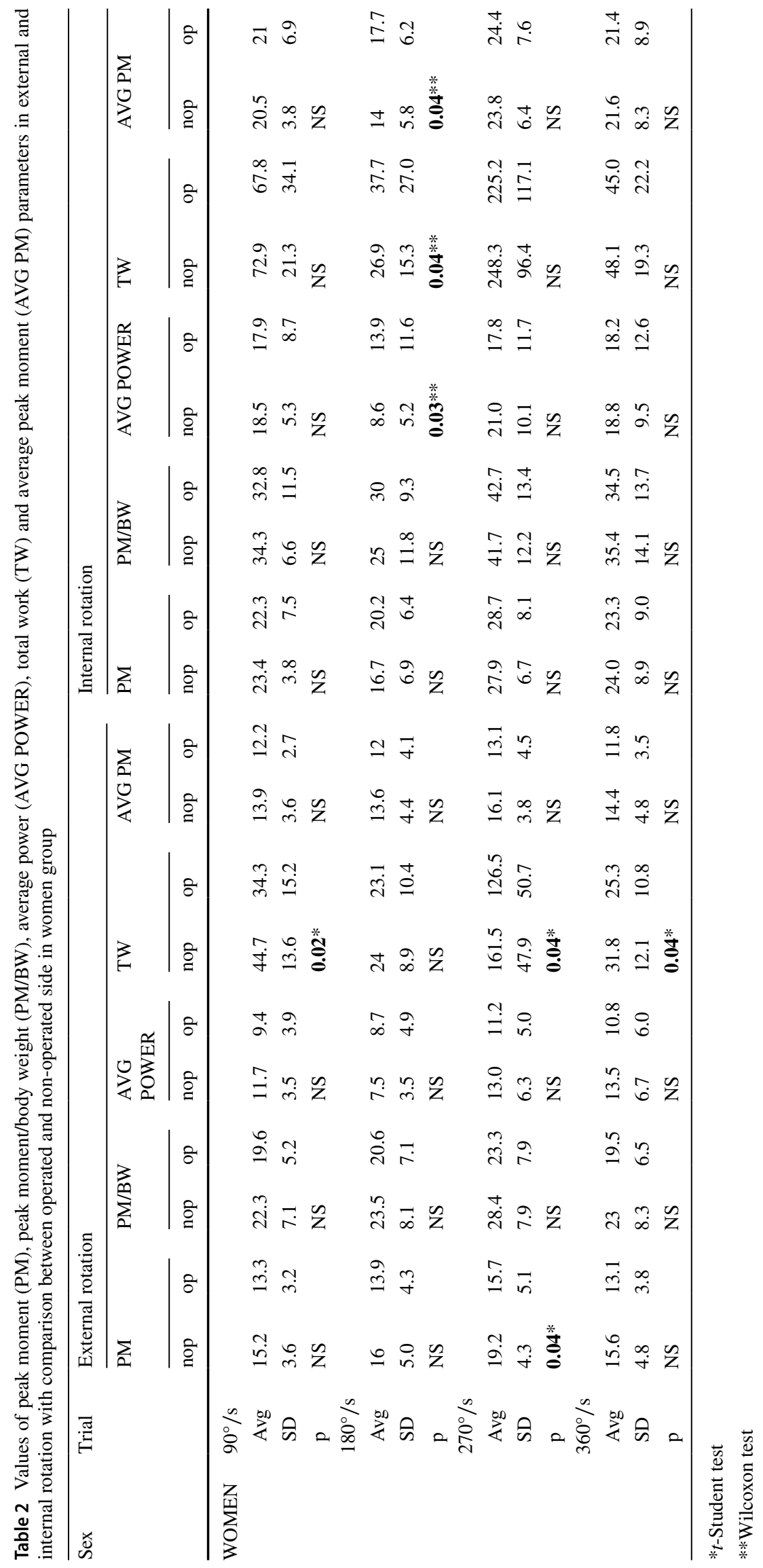


Open Access This article is licensed under a Creative Commons Attribution 4.0 International License, which permits use, sharing, adaptation, distribution and reproduction in any medium or format, as long as you give appropriate credit to the original author(s) and the source, provide a link to the Creative Commons licence, and indicate if changes were made. The images or other third party material in this article are included in the article's Creative Commons licence, unless indicated otherwise in a credit line to the material. If material is not included in the article's Creative Commons licence and your intended use is not permitted by statutory regulation or exceeds the permitted use, you will need to obtain permission directly from the copyright holder. To view a copy of this licence, visit http://creativecommons.org/licenses/by/4.0/.

Publisher's Note Springer Nature remains neutral with regard to jurisdictional claims in published maps and institutional affiliations. 